\title{
ELECTRICAL CHARACTERISTICS OF AU SCHOTTKY CONTACTS EVAPORATED ON PULSED ELECTRON BEAM ANNEALED N-TYPE (IOO) SILICON
}

\author{
M.S. Doghmane, D. Barbier and A. Laugier \\ Laboratoire de Physique de Za Matière (LA 358), Institut National des \\ Sciences Appliquées de Lyon, 20, Avenue Albert Einstein, \\ 69621 Vizzeurbanne Cedex, France
}

\section{RESUME}

Des diodes Schottky ont été réalisées sur du silicium de type $\mathbf{N}$ dont la surface a subi un recuit par bombardement électronique pulsé (P.E.B.A.) Au-delà d'un seuil situé aux environs de $1.0 \mathrm{~J} / \mathrm{cm}^{2}$, le recuit P.E.B.A. provoque une for te détérioration des caractéristiques électriques des diodes, une diminution de la barrière de potentiel au contact $\mathrm{Au}-\mathrm{Si}(\mathrm{N})$ et une augmentation rapide du facteur d'idéalité. Des mesures de capacités montrent qu'une forte concentration de donneurs est introduite par le recuit P.E.B.A. Leur concentration superficielle, pouvant dépasser $10^{16} \mathrm{~cm}^{-3}$, et leur profil ont été déterminés par des oxydations anodiques successives. En outre, une amélioration sensible des caractéristiques des diodes est obtenue lorsque le traitement P.E.B.A. est suivi d'un recuit thermique isochrone sous hydrogène durant 30 minutes jusqu'à $600^{\circ} \mathrm{C}$.

\section{ABSTRACT}

Gold Schottky contacts were deposited on Pulsed Electron Beam Annealed (P.E.B.A.) virgin $\mathrm{N}$-type $(100)$ silicon. Above a $1 \mathrm{~J} / \mathrm{cm}^{2}$ fluence threshold a strong degradation of the Schottky diodes I(V) characteristics has been observed with a drop of the barrier height and a fast increase of the ideality factor. Moreover, capacitance measurements combined with oxide stripping have shown that donor centers in excess of $10^{16} \mathrm{~cm}^{-3}$ are generated in the P.E.B.A. induced regrowth layer. Isochronal thermal annealing under $\mathrm{H}_{2}$ atmosphere was performed on P.E.B.A. processed samples before depositing the Gold contacts. Improvement of the diode characteristics have been obtained when increasing the annealing temperature up to $600^{\circ} \mathrm{C}$.

\section{INTRODUCTION}

Among other fast liquid phase epitaxy processes Pulsed Electron Beam Annealing (P.E.B.A.) has been successfully used to activate implanted dopants in silicon $/ 1,2 /$. However, pulsed laser or electron beam annealing is generally accompanied by electrically active defects generation in the regrowth layer $13 \%$. In a previous work DLTS measurements have shown that various majority carrier traps are induced by P.E.B.A. depending on the electron beam parameters $/ 4 \%$.

In this work, the degradation of Au/Si Schottky diodes made on P.E.B.A. processed (100) $\mathrm{N}$-type silicon has been studied as a function of the electron beam parameters (Energy deposition profile-fluence). The effect of a post-P.E.B.A. isochronal thermal treatment under $\mathrm{H}_{2}$ atmosphere was also investigated in order to study the induced defects annealing behaviour.

\section{EXPERIMENT}

Czochralski grown (100) N-type silicon wafers 3 to $10 \Omega . \mathrm{cm}$ in resistivity were first $\mathrm{HF}$ rinsed and then annealed with 50 ns duration electron beam pulses under cryogenic vacuum using a SPIRE 300 pulsed electron beam processor. This machine is described in ref.2. It allows for polykinetic electron beam parameters adjustment by mean of the field emission diode perveance which is controlled by the $r / d_{0}$ ratio, $r$ being the cathode radius and $d_{0}$ the cathode-anode distance. In this work, two values of the $r / d_{0}$ ratio were selected resulting in a rather penetrating electron depth-dose profile for pulse $n^{\circ} 1\left(r / d_{0}=7.3\right.$, mean electron energy $=$ 
$15 \mathrm{keV})$ and in a sharper electron depth-dose profile for pulse $n^{\circ} 2\left(r / d_{0}=6.5\right.$, mean electron energy $=12 \mathrm{keV})$. For each electron pulses the beam fluence has been varied from 0.8 to $1.5 \mathrm{~J} / \mathrm{cm}^{2}$. After P.E.B.A. Al back contacts were evaporated and annealed for $15 \mathrm{mn}$ at $150^{\circ} \mathrm{C}$. Finally, the Au contact was evaporated on the P.E.B.A. processed area. Reference diodes made on non-P.E.B.A. processed silicon exhibit good and reproducible rectifier characteristics.

\section{RESULTS}

The I(V) characteristics of Schottky diodes made on pulse $n^{\circ} 1$ processed silicon are plotted on Fig. 1 as a function of the beam fluence. The rectifier effect desappears at $1.1 \mathrm{~J} / \mathrm{cm}^{2}$ and the ideality factor $n$ which was 1.16 for the reference diode reache values as high as 2.7 at only $1.2 \mathrm{~J} / \mathrm{cm}^{2}$ as shown on Fig.2. On the same figure is also plotted the values of $n$ versus fluence for diodes made on pulse $n^{\circ} 2$ processed silicon. We notice the same threshold around $1 \mathrm{~J} / \mathrm{cm}^{2}$ whatever the type of electron beam pulse but the ideality factor remains slightly lower for pulse $n^{\circ} 2$ compared to pulse $n^{\circ} 1$.

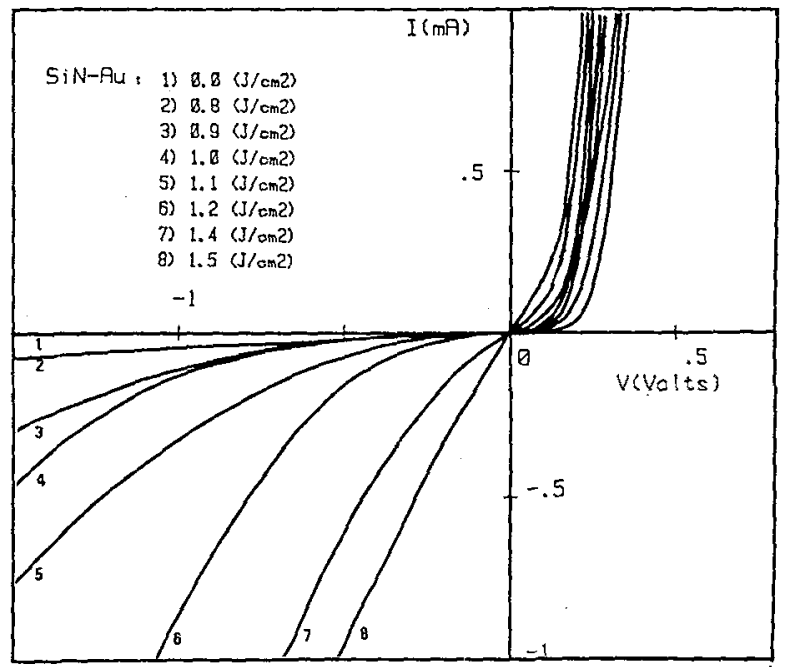

Fig.1 - I(V) characteristics of Au/Si-N Schottky diodes made on silicon processed with electron beam pulse $n^{\circ} 1$ at variable fluence.

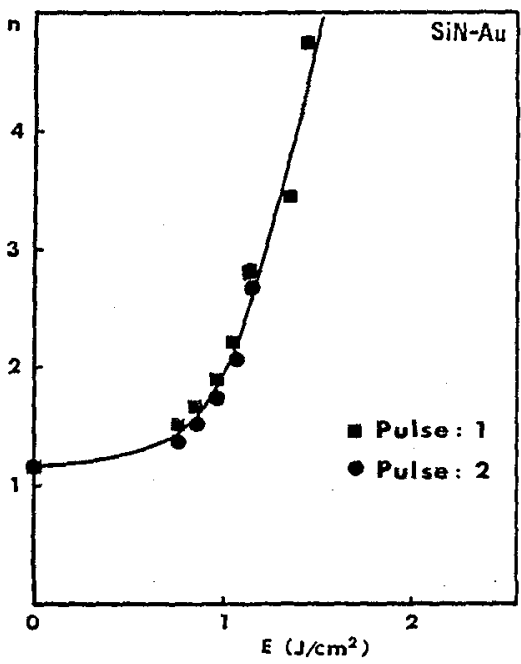

Fig.2 - Evolution of the diode ideality factor $n$ versus fluence 
Fig. 3 shows the evolution versus fluence of the barrier height $\mathrm{Vbn}$ as deduced from the saturation current Is. Higher values are obtained for pulse $n^{\circ} 2$ compared to pulse $n^{\circ} 1$ indicating the same trend as for the ideality factor evolution. $C(V)$ measurements have been carried out at $1 \mathrm{MHz}$ and Fig.4 shows the fast increase of the measured capacity at $-0.5 \mathrm{~V}$ above $1 \mathrm{~J} / \mathrm{cm}^{2}$. This result is coherent with the degradation threshold deduced from $\mathrm{I}(\mathrm{V})$ curves of Fig.1.

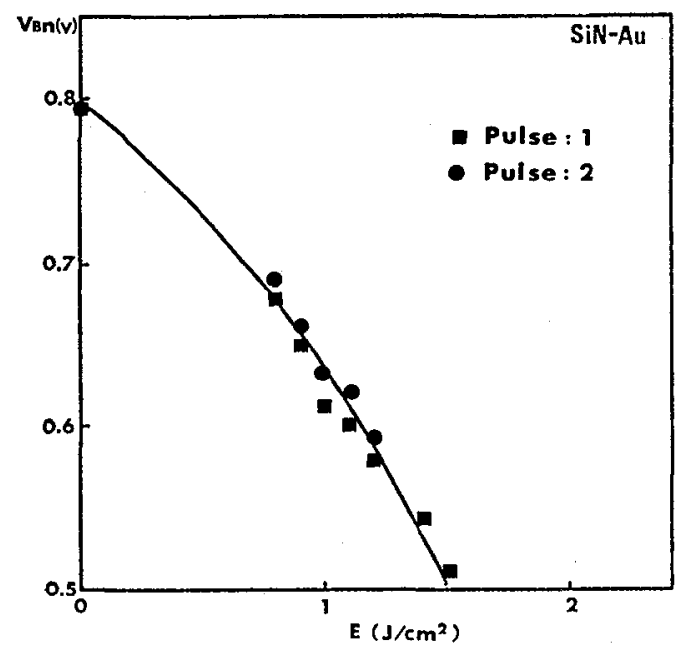

Fig.3 - Evolution of the barrier height $V_{b n}$ versus fluence

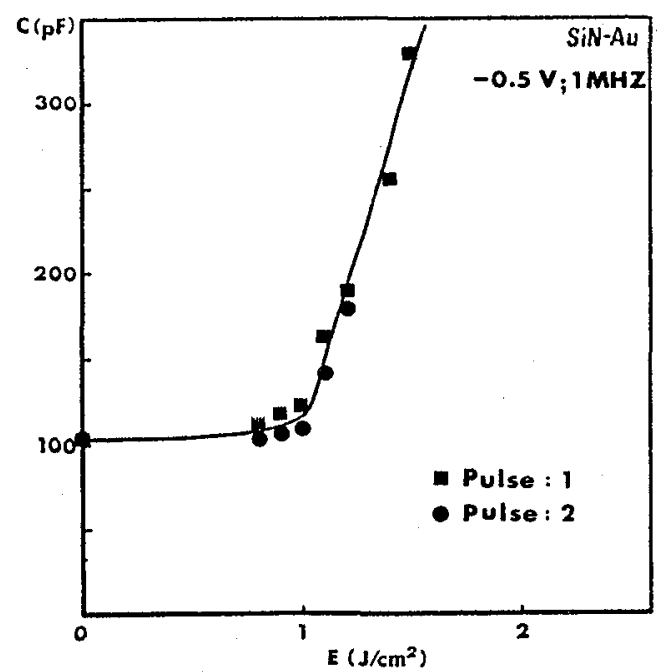

Fig.4 - Evolution of the diode capacity at $-0.5 \mathrm{~V}$ as a function of the beam fluence.

Oxide stripping of the P.E.B.A. processed silicon layer was performed in order to investigate the diode characteristics evolution as a function of depth. Au contacts were deposited at each step after removal of a $15 \mathrm{~nm}$ thick oxide layer. At only $90 \mathrm{~nm}$ beneath the initital surface the $I(V)$ curve of a Schottky diode made on silicon which has been processed with pulse $\mathrm{n}^{\circ} \mathrm{l}$ at $1.2 \mathrm{~J} / \mathrm{cm}^{2}$ is very close to the one measured with a reference diode. The ideality 
factor recovers a value of 1.25 and the barrier height rises from $0.57 \mathrm{~V}$ to $0.7 \mathrm{~V}$. Fig. 5 shows the decrease of the capacitance measured at $-1 \mathrm{~V}$ after each $15 \mathrm{~nm}$ silicon removal. One can observe that the reference diode capacitance is recovered at about $90 \mathrm{~nm}$. A good-fit of the depth-capacitance curve of Fig.5 has been carried out using an exponential defect concentration profile $15 /$. This leads to donor centers surface concentration in excess of $10^{16} \mathrm{~cm}^{-3}$. In addition capacitance measurements after oxide stripping of silicon samples processed with pulse $n^{\circ} 2$ at $1.2 \mathrm{~J} / \mathrm{cm}^{2}$ indicates that the donor profile extends deeper than $90 \mathrm{~nm}$. This result can be related to the differences in the P.E.B.A. induced thermal effects between the two types of electron beam pulse as will be discussed in the next section.

Moreover, table I shows the evolution of the diode characteristics when P.E.B.A. is followed by a $30 \mathrm{mn}$ thermal treatment under $\mathrm{H}_{2}$ atmosphere. Al and Au contacts were deposited after thermal annealing. Considerable improvement of the diode characteristics is observed when the annealing temperature is increased from $300^{\circ} \mathrm{C}$ to $600^{\circ} \mathrm{C}$. But even at this temperature the typical parameters of a reference diode are not completely recovered.

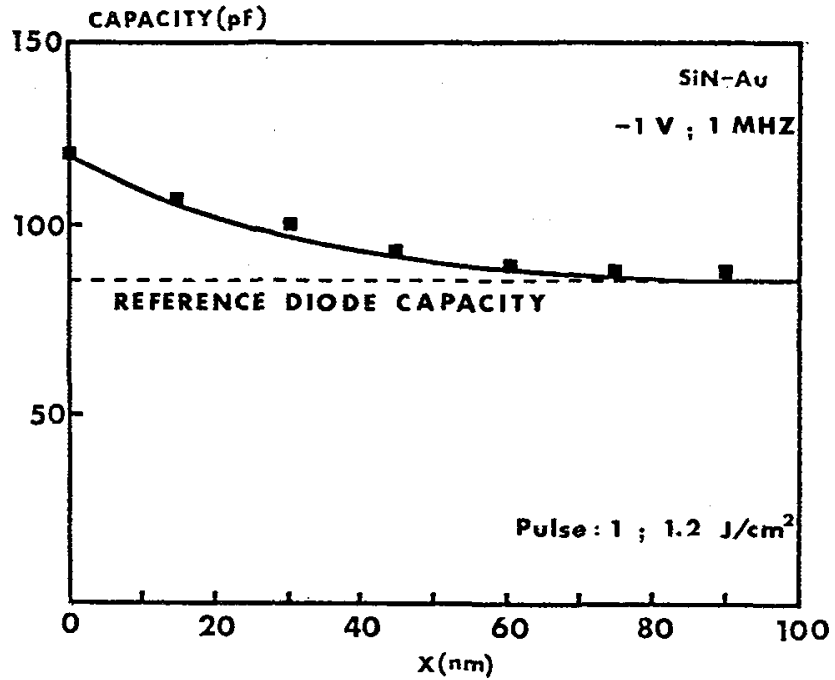

Fig.5 - Diode capacitance at $-1 \mathrm{~V}$ as a function of the removed silicon layer thickness.

\begin{tabular}{|c|c|c|c|c|}
\hline $\begin{array}{c}\text { Annealing } \\
\text { Temperature } \\
{ }^{\circ} \mathrm{C}\end{array}$ & $\begin{array}{c}\text { Ideality } \\
\text { Factor }\end{array}$ & $\mathrm{I}_{\mathrm{s}}\left(\mathrm{A} / \mathrm{cm}^{2}\right)$ & $\begin{array}{c}\text { Capacity }(\mathrm{pF}) \\
-1 \mathrm{~V} ; 1 \mathrm{MHz}\end{array}$ & $\mathrm{V}_{\mathrm{bn}}(\mathrm{V})$ \\
\hline 20 & 2.92 & $3.3510^{-3}$ & 165.2 & 0.570 \\
\hline 300 & 2.85 & $2.2110^{-3}$ & 153.2 & 0.580 \\
\hline 400 & 1.96 & $1.0310^{-3}$ & 124.2 & 0.600 \\
\hline 500 & 1.73 & $9.7610^{-4}$ & 119.9 & 0.601 \\
\hline 550 & 1.64 & $7.7610^{-4}$ & 106.8 & 0.612 \\
\hline 600 & 1.52 & $1.0810^{-4}$ & 97.8 & 0.660 \\
\hline $\begin{array}{l}\text { Reference } \\
\text { diode }\end{array}$ & 1.16 & $6.6010^{-7}$ & 89.7 & 0.791 \\
\hline
\end{tabular}

Table 1 - Evolution of the diode parameters after a $30 \mathrm{mn}$ thermal treatment under $\mathrm{H}_{2}$ atmosphere at variable temperature. 


\section{DISCUSSION}

For a beam fluence lower than $1 \mathrm{~J} / \mathrm{cm}^{2}$ P.E.B.A. produces only a small change in the $\mathrm{Au} / \mathrm{Si}-\mathrm{N}$ Schottky diode electrical parameters. However, above this threshold a fast degradation occurs with the two types of electron beam pulses used in this work. The sharp increase of the capacitance measured at $-1 \mathrm{~V}$ indicates that donor centers are induced by P.E.B.A. in high concentration in the silicon regrowth layer. They exhibit a steep profile which is more penetrating in the case of pulse $n^{\circ} 2$ processed samples. Computer simulation have shown that for fluences higher than $1 \mathrm{~J} / \mathrm{cm}^{2}$ the silicon surface layer turns into melt either for pulse $n^{\circ} 1$ or for pulse $n^{\circ} 2 / 6 /$. However, at $1.2 \mathrm{~J} / \mathrm{cm}^{2}$, the P.E.B.A. induced fully molten depth is $0.6 \mu \mathrm{m}$ for pulse $\mathrm{n}^{\circ} 2$ while it is only $0.1 \mu \mathrm{m}$ for pulse $n^{\circ} 1$. So we think that the most damaging defects are generated in the P.E.B.A. induced molten layer. Because of the improvement obtained with the post-P.E.B.A. thermal treatment up to $600^{\circ} \mathrm{C}$ we suggest that quenched-in point defects are mostly responsible for the diodes degradation.

Moreover, Patel et al. have shown that dislocations could be annealed only at temperatures higher than $700^{\circ} \mathrm{C} / 7 /$. So, the residual diode degradation after P.E.B.A. plus $600^{\circ} \mathrm{C}$ thermal treatment under $\mathrm{H}_{2}$ atmosphere could be related either to residual point defects not annealed below $600^{\circ} \mathrm{C}$ or more probably to dislocations. These have been recently observed by mean of electron microscopy in the P.E.B.A. induced melting layer $/ 8 /$.

\section{v. CONCLUSION}

Gold Schottky diodes made on P.E.B.A. processed $\mathrm{N}$-type silicon exhibit fast degradation above a $1 \mathrm{~J} / \mathrm{cm}^{2}$ fluence threshold. The highly damage layer coincides with the P.E.B.A. induced molten layer where donor centers are likely to be generated during the freezing process. However, a post-P.E.B.A. thermal treatment at $600^{\circ} \mathrm{C}$ during $30 \mathrm{mn}$ in the presence of molecular hydrogen is not sufficient to recover the typical parameters of a $\mathrm{Au} / \mathrm{Si}-\mathrm{N}$ reference diode.

\section{REFERENCES}

/1/ GREENWALD A.C., KIRKPATRICK A.R., LITTLE R.G., MINNUCCI J.A., J. Appl. Phys. 50, 2 (1979) 783.

12/ BARBIER D., LAUgier A., CACHARD A., J. de Physique, Col.C5, Suppl.n²12, 43 (1982) 411.

13/ KIMMERLING L.C., BENTON J.L., Proceedings of the MRS Symposium : Laser and Electron Beam Processing of Materials, Academic Press (1980) 385.

14/ BARBIER D., KECHOUANE M., CHANTRE A., LAUGIER A., Proceedings of the MRS Symposium: Laser-Solid interactions and transient thermal processing of Materials, Elsevier (1982) (to be published)

15/ PONPON J.P., BUTTUNG E., SIFFERT P., Rev.Phys.Appl. 17 (1982) 687.

16/ CHEMISKY G., BARBIER D., LAUGIER A., (see this symposium)

17/ PATEL J.R., KIMMERLING L.C., J. de Phys., Col.C6, Suppl.n6, 40 (1979) 67.

/8/ THOLOMIER M., PITAVAL M., AMBRI M., J.Appl.Phys. 푸, 3 (1983) 1588. 